\title{
Pilne przeszczepienie serca u 42-letniej chorej po nagłym zatrzymaniu krążenia w przebiegu pozapalnej kardiomiopatii rozstrzeniowej
}

\section{Urgent heart transplant in a 42-year-old woman after a sudden cardiac arrest in the course of post-inflammatory dilated cardiomyopathy}

\author{
Joanna Zychowicz, Janusz Sielski \\ Wojewódzki Szpital Zespolony, Świętokrzyskie Centrum Kardiologii w Kielcach
}

\section{Streszczenie}

Pozapalna kardiomiopatia rozstrzeniowa (DCM) jest powikłaniem zapalenia mięśnia sercowego i schorzeniem, które może prowadzić do ciężkiej niewydolności serca. Autorzy przedstawili opis przypadku 42-letniej kobiety, wcześniej nieleczonej z powodu chorób przewlekłych, bez obciążającego wywiadu rodzinnego, z wywiadem licznych infekcji górnych dróg oddechowych powikłanych pozaplaną DCM, u której doszło do nagłego zatrzymania krążenia w przebiegu częstoskurczu torsade de pointes oraz migotania komór.

Słowa kluczowe: pozapalna kardiomiopatia rozstrzeniowa, zapalenie mięśnia sercowego, infekcje górnych dróg oddechowych

Folia Cardiologica 2017; 12, 2: 204-207

\section{Wstęp}

Nagłe zatrzymanie krążenia (SCA, sudden cardiac arrest) definiuje się jako zatrzymanie mechanicznej czynności serca powodujące ustanie krążenia krwi [1]. Nagłe zatrzymanie krążenia cechuje brak wyczuwalnego tętna na obwodzie, czemu towarzyszą bezdech lub oddech agonalny oraz brak reakcji chorego na bodźce zewnętrzne. Przyczyną tego nagłego stanu chorobowego jest ustanie funkcji jednego z układów - oddechowego, krążenia lub ośrodkowego układu nerwowego [1]. Według statystyk w Europie dochodzi do 700000 zgonów z powodu SCA w ciągu roku. Z tej liczby 275000 SCA występuje poza szpitalem. W Stanach Zjednoczonych SCA pozaszpitalne stanowią 375000 przypadków rocznie [2]. Najczęstszą przyczyną SCA jest choroba niedokrwienna serca. Do pozostałych przyczyn zalicza się kardiomiopatie, anomalie naczyń wieńcowych i ścian naczyń, mosty mięśniowe. Najczęściej SCA ma podłoże kardiologiczne, ale może również wystąpić u osób bez strukturalnej choroby serca [3].

Pozapalna kardiomiopatia rozstrzeniowa (DCM, dilated cardiomyopathy) jest powikłaniem zapalenia mięśnia sercowego (myocarditis) i schorzeniem, które może prowadzić do ciężkiej niewydolności serca. Niekiedy się zdarza, że zakażenie wirusowe ustępuje, a zapalenie mięśnia sercowego utrzymuje się z powodu nadmiernej reakcji immunologicznej organizmu. Zapalenie mięśnia sercowego najczęściej powodują wirusy, na przykład wirus Coxackie B1-B5, wirusy grypy A i B, różyczki, wirus ospy wietrznej i półpaśca [4, 5].

W pracy opisano przypadek 42-letniej nauczycielki, która doznała SCA w szkole podczas zajęć lekcyjnych. Pierwszymi osobami, które podjęły skuteczną resuscytację krążeniowo-oddechową, byli uczeń VI klasy oraz inna nauczycielka. Dzięki zaistnieniu sekwencji korzystnych zdarzeń pacjentkę ostatecznie zakwalifikowano do pilnego przeszczepienia serca. Zabieg wykonano i obecnie chora czuje się dobrze.

Adres do korespondencji: lek. Joanna Zychowicz, Wojewódzki Szpital Zespolony, Świętokrzyskie Centrum Kardiologii, ul. Grunwaldzka 45, 25-736 Kielce, joannaz86@onet.pl 


\section{Opis przypadku}

Chora w wieku 42 lat, dotychczas nieleczona z powodu chorób przewlekłych, bez obciążającego wywiadu rodzinnego, z wywiadem licznych infekcji górnych dróg oddechowych, została przyjęta na oddział intensywnego nadzoru kardiologicznego po nagłym SCA przedszpitalnym w mechanizmie migotania komór i długotrwałej reanimacji. Przy przyjęciu na oddział chora była w ciężkim stanie, nieprzytomna, zaintubowana, sztucznie wentylowana. W wykonanym badaniu elektrokardiograficznym (EKG) stwierdzono rytm zatokowy, blok lewej odnogi pęczka Hisa. W wykonanej tomografii komputerowej (CT, computed tomography) głowy nie zobrazowano istotnych zmian. W badaniu CT klatki piersiowej wykluczono zatorowość płucną. W badaniu echokardiograficznym stwierdzono powiększoną lewą komorę (wymiar końcoworozkurczowy lewej komory [LVEDd, left ventricular end-diastolic dimension] $70 \mathrm{~mm}$, wymiar końcowoskurczowy lewej komory [LVESd, left ventricular end-systolic dimension] $60 \mathrm{~mm}$ ) oraz rozległe odcinkowe zaburzenia kurczliwości pod postacią hipokinezy segmentu podstawnego i środkowego ściany przednio-bocznej, podstawnego segmentu ściany dolnej i dolno-bocznej, dyssynchronię skurczu lewej komory z frakcją wyrzutową 15-20\% (ryc. 1). W badaniach laboratoryjnych obserwowano narastające parametry martwicy mięśnia sercowe- go, istotnie podwyższone parametry zapalne oraz wzrost wartości peptydu netriuretycznego typu B. W wykonanej koronarografii nie stwierdzono istotnych zmian w naczyniach wieńcowych (ryc. 2).

W 1. dobie pobytu chorą rozintubowano. Pacjentka była przytomna w logicznym kontakcie. Ze względu na niską frakcję wyrzutową i duszność włączono leczenie kompensujące układ krążenia. Chora otrzymała dobutaminę i diuretyki. Włączono antybiotykoterapię - amoksacylinę z kwasem klawulonowym oraz ciprofloksacynę. W profilaktyce arytmii zastosowano amiodaron. Mimo stosowanego leczenia u chorej utrzymywał się zastój w krążeniu płucnym z towarzyszącą dusznością. W kolejnych dniach obserwowano zmniejszanie się parametrów zapalnych. Mimo stosowanego leczenia stan chorej pozostawał ciężki. Utrzymywały się zmiany zastoinowe w krążeniu płucnym z towarzyszącą dusznością. W kolejnych dniach obserwowano stabilizację parametrów zapalnych. Choć zoptymalizowano leczenie, to stan chorej pozostawał ciężki. Występowały duszność spoczynkowa oraz objawy niewydolności krążeniowo-oddechowej. U chorej wystąpiły epizody nieutrwalonego częstoskurczu komorowego o charakterze torsade de pointes oraz migotania komór. Pacjentka wymagała kilkukrotnych defibrylacji w celu przerwania arytmii (ryc. 3). Podjęto decyzję o implantacji kontrapulsacji wewnątrzaortalnej, by ustabilizować układ krążenia. Zabieg wykonano bez powikłań.
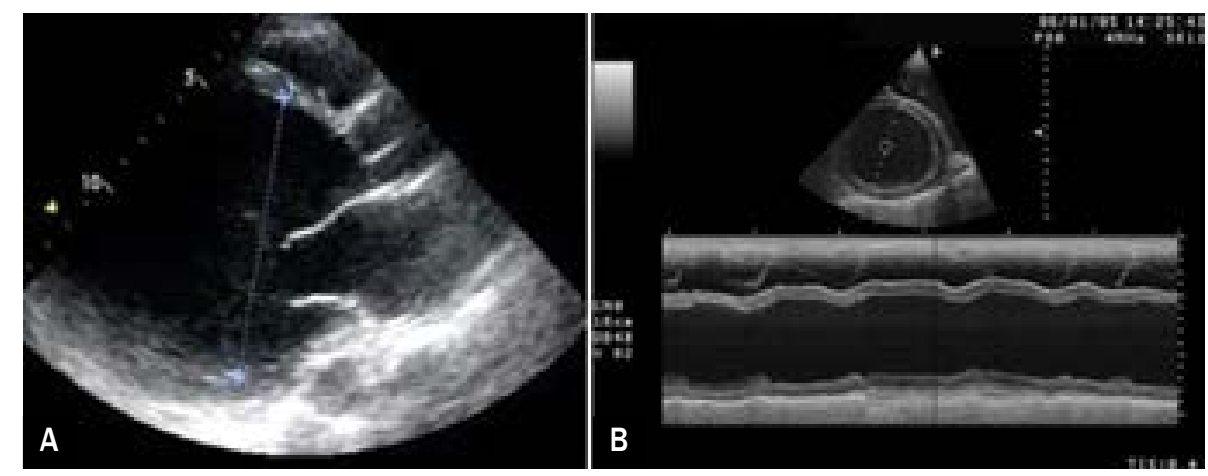

Rycina 1A, B. Zapis z badania echokardiograficznego: A. Projekcja przymostkowa w osi długiej - istotne poszerzenie mięśnia lewej komory; B. Projekcja M-mode

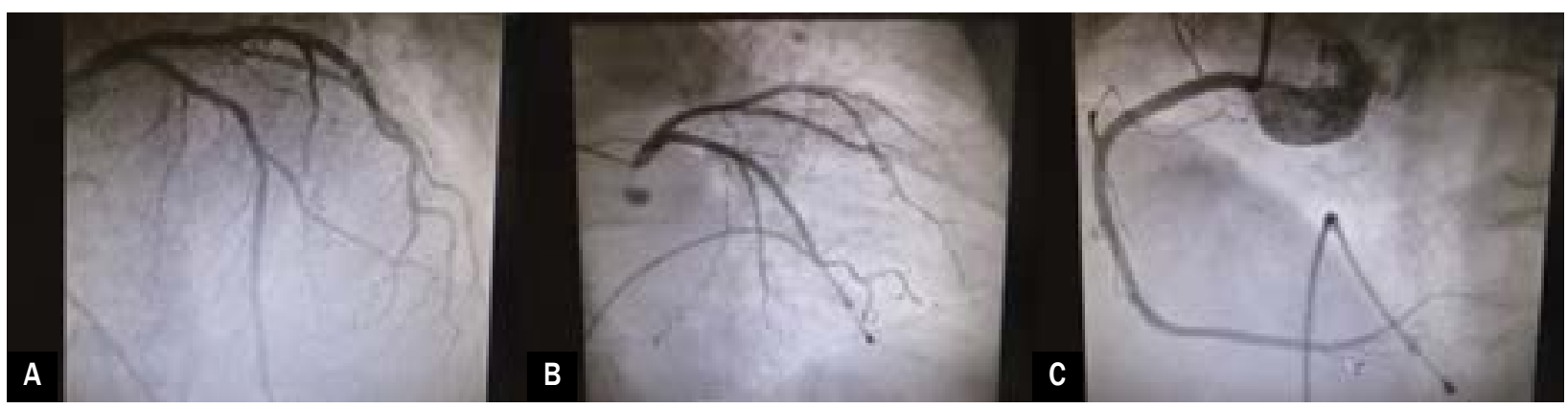

Rycina 2A-C. Obrazy z koronarografii - naczynia wieńcowe bez istotnych zmian: A, B. Arteriografia lewej tętnicy wieńcowej (LCA, left coronary artery); C. Arteriografia prawej tętnicy wieńcowej (RCA, right coronary artery) 

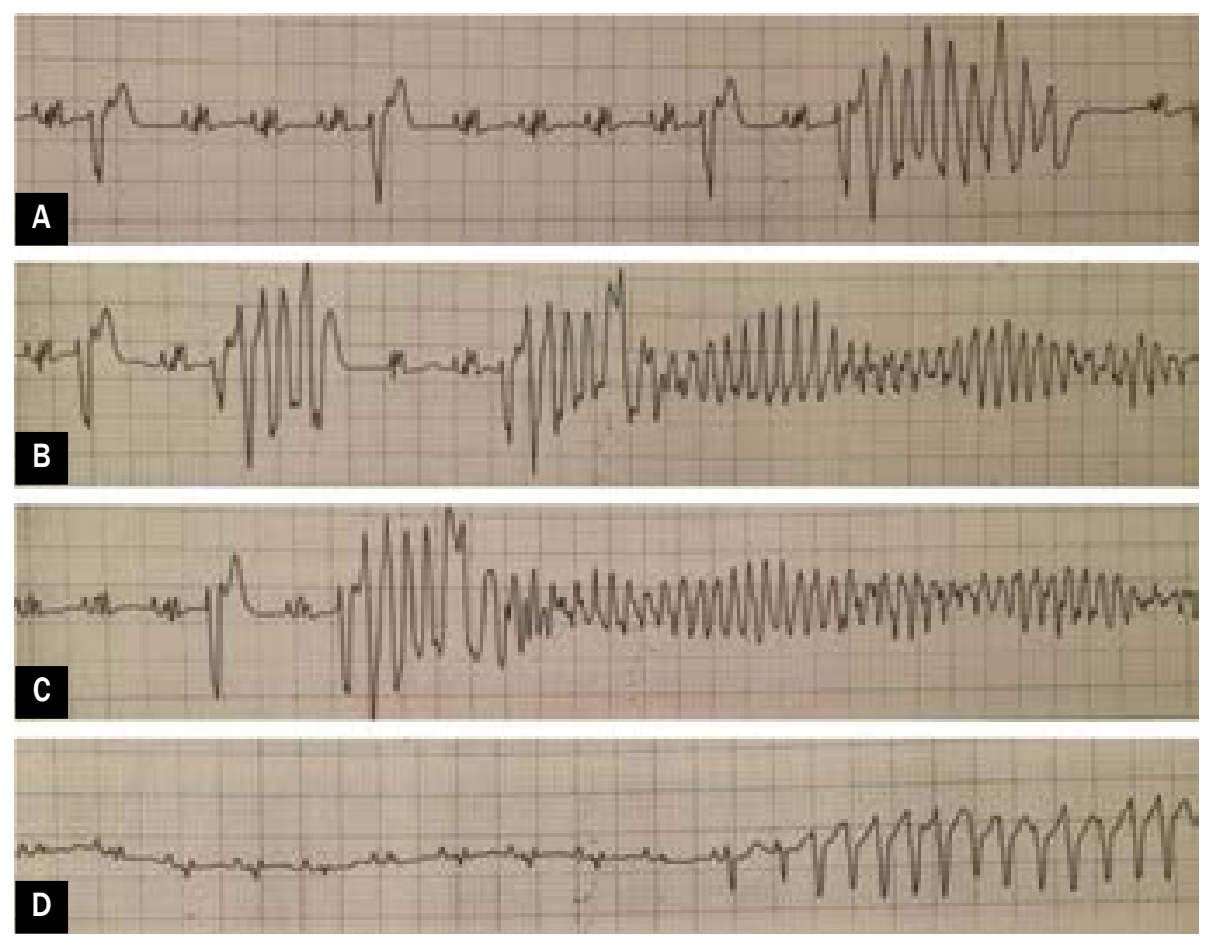

Rycina 3A-D. Zapisy elektrokardiograficzne z monitora (przed wykonaną defibrylacją) - polimorficzny częstoskurcz komorowy typu torsade de pointes

Stan chorej pozostawał ciężki. W 7. dobie pobytu, w celu dalszego leczenia, chorą skierowano do Śląskiego Centrum Chorób Serca w Zabrzu. By ustalić etiologię niewydolności serca, w klinice zabrzańskiej wykonano biopsję endomiokardialną. W badaniu histopatologicznym stwierdzono wieloogniskowy naciek zapalny z martwicą przylegających komórek mięśniowych i rozpoznano pozapalną DCM. Ze względu na nasilanie się objawów niewydolności serca mimo stosowanej farmakoterapii zastosowano mechaniczne wspomaganie krążenia - jako leczenie pomostowe przed transplantacją serca. W 15. dobie od SCA przeprowadzono z powodzeniem zabieg pilnego przeszczepienia serca.

\section{Dyskusja}

Transplantacja serca od lat (pierwszy pomyślny zabieg transplantacji serca i płuc przeprowadzono w 1981 r.) pozostaje metodą z wyboru w leczeniu ciężkiego, nieodwracalnego uszkodzenia mięśnia sercowego w sytuacji, gdy inne metody nie przynoszą efektu. Wskazaniem do transplantacji serca jest zaawansowana niewydolność krążenia, grożąca utratą życia w najbliższych miesiącach [6]. Do najczęstszych przyczyn przeszczepienia serca według Światowego Towarzystwa Transplantacji Serca i Płuc (ISHLT, International Society for Heart \& Lung
Transplantation) zalicza się uszkodzenie serca w wyniku zawału oraz pozapalną DCM. W ośrodkach amerykańskich około $50 \%$ chorych po transplantacji serca przeżywa co najmniej 10 lat, a po wyłączeniu chorych, którzy umierają w 1. roku po zabiegu (ok. 17,6\%), połowa przeżywa 12 lat, a $22,4 \%-17$ lat. W Polsce ponad $60 \%$ pacjentów przeżywa 5 lat, jednak w 1. roku po operacji śmiertelność wynosi około $20 \%$ [7,8]. Ważnym czynnikiem ryzyka przeżycia krótkoterminowego chorych po przeszczepieniu serca są wiek dawcy i biorcy oraz czas niedokrwienia. Na przeżycie długoterminowe wpływają natomiast wiek dawcy i biorcy, rasa biorcy oraz przyczyna niewydolności serca biorcy [7]. W Spanish Registry for Heart Transplantation dodatkowo wymienia się płeć biorcy, czas stosowania krążenia pozaustrojowego, funkcję nerek biorcy oraz przyczynę śmierci dawcy [7].

W ostatnim 10-leciu niewydolność serca stała się jednym z poważniejszych problemów zdrowotnych na świecie. W przypadkach zaawansowanej niewydolności serca, gdy farmakoterapia, pomostowanie aortalno-żylne czy rewaskularyzacja mięśnia sercowego nie przynoszą poprawy, chorzy są kwalifikowani do transplantacji serca. Liczba transplantacji serca wykonanych w ponad 240 ośrodkach na całym świecie według danych ISHLT wynosi około 55 000. W Polsce wykonuje się około 100 przeszczepień rocznie, co pokrywa $30-40 \%$ szacowanego zapotrzebowa- 
nia. Przez ostatnie 10 lat zdecydowaną większość biorców przeszczepu stanowili chorzy z ciężkim, pozawałowym uszkodzeniem mięśnia sercowego, a w dalszej kolejności chorzy z pozapalną kardiomiopatią. Obecnie stosunek liczby osób z chorobą wieńcową i kardiomiopatią wynosi po około $50 \%$ [9]. Niewielki odsetek stanowią nabyte i wrodzone wady serca oraz ponowne transplantacje $[6,10]$.

\section{Podsumowanie}

W opisanym przypadku, ze względu na młody wiek pacjentki, progresję objawów zastoinowej niewydolności serca, wyczerpanie farmakologicznych metod leczenia oraz duże ryzyko SCA, zdecydowano o zakwalifikowaniu chorej do pilnego przeszczepienia serca.

\section{Abstract}

Post-inflammatory dilated cardiomyopathy (DCM) is a complication of inflammatory myocarditis and a disease that can lead to severe heart failure. The authors presented a case report of a 42-year-old woman previously not treated for chronic diseases, without family history, with the history of many upper respiratory tract infections complicated by DCM in which there has been a sudden cardiac arrest in the course of tachycardia torsades de pointes, and ventricular fibrillation.

Key words: post-inflammatory dilated cardiomyopathy, myocarditis, upper respiratory tract infections

Folia Cardiologica 2017; 12, 2: 204-207

\section{Piśmiennictwo}

1. Szczeklik A, Tendera M. Kardiologia. Tom II. Medycyna Praktyczna, Kraków 2010: 1033-1042.

2. Centers for disease control: National Center for Health Statistics: Data WareHouse. http://www.cdr.gov/nchs/datawh.htm (6.02.2017).

3. 2005 American Heart Association guidelines for cardiopulmonary resuscitation and emergency cardiovascular care. Part 7.2: Management of cardiac arrest. Circulation. 2005; 112((24 suppl)): IV-58-IV66, doi: 10.1161/circulationaha.105.166557.

4. Cooper LT. Myocarditis. N Engl J Med. 2009; 360(15): 1526-1538, doi: 10.1056/NEJMra0800028, indexed in Pubmed: 19357408.

5. Feldman AM, McNamara D. Myocarditis. N Engl J Med. 2000; 343(19): 1388-1398, doi: 10.1056/NEJM200011093431908, indexed in Pubmed: 11070105.
6. Korewicki J, Browarek A, Zieliński T, et al. Rokowanie chorych z ciężką niewydolnością serca, wstępnie kwalifikowanych do przeszczepu serca - na podstawie danych ogólnopolskiego rejestru POLKARD 20032005. Kardiochir Torakochir. 2006; 3(3): 308-322.

7. Religa Z. Zarys kardiochirurgii. Wydawnictwo Lekarskie, PZWL, Warszawa 1993: 292-304.

8. Luckraz H, Goddard M, Charman SC, et al. Early mortality after cardiac transplantation: should we do better? J Heart Lung Transplant. 2005; 24(4): 401-405, doi: 10.1016/j.healun.2004.02.013, indexed in Pubmed: 15797739.

9. Mancini M, Gangahar D. Heart transplantation. Medicine. 2005; 1: 1-11.

10. Zakliczyński M, Zembala M. Postępy w przeszczepianiu serca. Medipress Kardiol. 2001; 3: 39-46. 